\title{
ARTIGOS
}

Recebido em 30.11.2012. Aprovado em 04.06.2013

Avaliado pelo sistema double blind review. Editor Científico: Mário Sacomano Neto

DOI: http://dx.doi.org/10.1590/So034-759020140306

\section{EMPREENDEDORISMO, MARGINALIDADE E ESTRATIFICAÇÃO SOCIAL}

\author{
Entrepreneurship, marginality and social stratification \\ Emprendedorismo, marginalidad y estratificación social
}

\section{RESUMO}

A história do empreendedorismo mostra o papel relevante dos grupos sociais mais marginalizados, na tentativa de inserção social. Apesar disso, tal tema permanece praticamente explorado no Brasil. Nesse contexto, insere-se o presente trabalho, que buscou identificar o estrato social de origem de empreendedores industriais, localizados em Belo Horizonte, e o padrão de mobilidade intergeracional aí presente. Utilizou, para isso, uma pesquisa amostral de natureza quantitativa, complementada por informações qualitativas. Os resultados indicam que o empreendedorismo, no universo pesquisado, não constitui um fenômeno de elite. Encontra-se associado às classes média-baixa e baixa, e tal fato influencia a motivação para a criação de empreendimentos. Ao mesmo tempo, quanto menor o estrato social de origem dos empreendedores, maiores as chances de ocorrer mobilidade social vertical. 0 artigo lança luzes sobre o papel do empreendedorismo como fator de mobilidade social e abre caminhos para novas pesquisas na área.

PALAVRAS-CHAVE | Empreendedor, marginalidade, mobilidade, classe social, estrato social.

\begin{abstract}
Entrepreneurship history enlivens the role of marginalized social groups in their attempts at social insertion. Nowadays, there is scanty a body of researches about entrepreneurship and social stratification, particularly in Brazil. This article stems from a survey, carried out in Belo Horizonte, Brazil, as it focused on the original social layers of local industrial entrepreneurs as well as it correlated to the pattern of inter-generational mobility (fathers to sons) therein. Drawing from our empirical research it may be posited: i.) entrepreneurship doesn't tend to be a pathway pursued by the elite, being mostly a lower-middle class phenomenon; ii.) the lower the original social stratum, the bigger the chances of inter-generational social vertical mobility. The results shed lights on role of entrepreneurship as a way to social mobility.
\end{abstract}

KEYWORDS / Entrepreneur, marginalization, mobility, social stratification, social class.

\section{RESUMEN}

La historia del emprendedorismo muestra el papel relevante de los grupos sociales más marginalizados, en el intento de inserción social. A pesar de esto, dicho tema permanece prácticamente explotado en Brasil. En ese contexto, ingrese el presente trabajo, que buscó identificar el estrato social de origen de emprendedores industriales, ubicados en Belo Horizonte, y el padrón de movilidad intergeneracional ahí presente. Utilizó, para esto, una encuesta por muestra de naturaleza cuantitativa, complementada por informaciones cualitativas. Los resultados indican que el emprendedorismo, en el universo estudiado, no constituye un fenómeno de elite. Se encuentra asociado a las clases media-baja y baja, y tal hecho influencia la motivación para la creación de emprendimientos. Al mismo tiempo, cuanto menor el estrato social de origen de los emprendedores, mayores las posibilidades que se produzca movilidad social vertical. El artículo aclara sobre el papel del emprendedorismo como factor de movilidad social y abre caminos para nuevos estudios en el área.

PALABRAS CLAVE / Emprendedor, marginalidad, movilidad, clase social, estrato social. 


\section{INTRODUÇÃO}

A história do empreendedorismo vem mostrando o papel relevante reservado aos grupos sociais marginalizados (Sombart, 1928, 2001), muitas vezes originários de comunidades de imigrantes, nas conquistas econômicas. Foi o caso dos libaneses na África Ocidental, dos chineses na Ásia do Sudeste, dos indianos na África Oriental etc. (Hoselitz, 1951; Jones \& Wadhwani, 2006). No Brasil, a historiografia econômica e empresarial, embora limitada, também registra a presença de fenômeno semeIhante. Os grandes empuxos industriais no País, que vieram, sobretudo, a partir de iniciativas governamentais - a exemplo das implementadas pelo Governo Vargas - estimularam o desenvolvimento de um capitalismo de estado, por meio da criação de grandes empresas de base. Apesar da prioridade reservada ao capitalismo de estado, alguns empreendedores tiveram um papel destacado no processo de industrialização do País.

Os fundadores dos grandes impérios industriais privados foram, muitas vezes, imigrantes pobres ou filhos de imigrantes, até mesmo semianalfabetos, que, com obstinação e espírito de luta, conseguiram projetar-se no mundo dos negócios, a exemplo das famílias Matarazzo, Lorenzetti, Gianetti, Pignatari (Marcovich, 2007). Trabalhos sobre empreendedorismo étnico no Brasil são raros (Pereira, 1964; Truzzi \& Neto, 2004). Pereira (1964), por exemplo, ao abordar o caso de grandes e médios empresários da cidade de São Paulo e da região do $A B C$, observa o papel relevante desempenhado por uma geração de imigrantes. Truzzi e Neto (2004), por seu lado, realizam um estudo enfocando o papel dos imigrantes na experiência de industrialização de São Paulo. Martes (2009, p. 26), ao analisar o empreendedorismo étnico, salienta que, "na presente fase de globalização, a mão de obra imigrante e as economias étnicas são fundamentais, especialmente nas metrópoles globais".

Vários estudiosos contemporâneos do fenômeno de mudança social e empreendedorismo vêm buscando compreender a influência da afiliação a diferentes grupos sociais, minoritários ou marginalizados, na formação do espírito empreendedor (Jones \& Wadhwani, 2006; Volery, 2007). Para muitos autores clássicos, o empreendedorismo não seria um fenômeno originário da elite da sociedade (Hoselitz, 1959; Kilby, 1971; Simmel, 2005; Sombart, 2001). Nos seus estudos sobre o papel do empreendedor nas transformações sociais, Hoselitz (1959) observa, no caso de países da América Latina, o espaço relevante reservado aos indivíduos marginalizados. Para Hagen (1962), tal situação explicar-se-ia pela preferência da elite, em muitas sociedades, em perseguir carreiras de estado ou empregos em grandes organizações, dotados de maior prestígio social.
No contexto atual, o conceito de marginalidade pode ser ampliado para incluir, além de grupos minoritários e comunidades de imigrantes, também uma parcela da população proveniente de estratos sociais inferiores da sociedade e, como tal, desprovidos, muitas vezes, de condições adequadas de escolaridade, renda e trabalho (Aldridge, Kenway, Maclness \& Parckh, 2012; Auer, Efendioglu \& Leschke, 2005; Beloque, 2007; DeVerteuil, 2009; McCarthy, 2011; Werfhorst \& Salverda, 2012; Zhao, 2012). Sem condições de seguir carreiras mais tradicionais e, ao mesmo tempo, desprovidos de laços com as elites locais, muitos indivíduos são compelidos ao empreendedorismo como uma alternativa de inserção e mobilidade social. Volery (2007) já observava que grupos sociais marginalizados recorrem, muitas vezes, ao autoemprego, como forma de inserção e mobilidade econômica. No mundo contemporâneo, muitos dos empreendedores não conseguiram engajar-se, previamente, em profissões e carreiras revestidas, tradicionalmente, de prestígio social. Ao serem alijados - à maneira de um novo tipo de "dissidente" - das oportunidades associadas às funções tradicionais, dirigem seus interesses para um espaço possível, cada vez mais difundido - o empreendedorismo.

Nem todos os autores, no entanto, concordam em associar o empreendedorismo ao status do homem marginal. Martinelli (2009), por exemplo, um ator contemporâneo, procura rever algumas proposições passadas, ao afirmar que as sociedades capitalistas modernas valorizam a capacidade de iniciativa e o ato de empreender. Nesse contexto, os empreendedores possuem maiores chances de vir de grupos centrais ou dominantes. No seu estudo sobre a Itália moderna, o autor enfatiza a importância das classes superiores - médias e altas - na formação dos novos empreendimentos no país. Se, de maneira geral, reflexões sobre empreendedorismo e estratificação social prosperaram muito no passado, existe, hoje, porém, carência de estudos, sobretudo de natureza empírica, tanto na literatura nacional quanto internacional corrente. 0 presente trabalho retoma tais reflexões, no contexto de uma pesquisa empírica, de natureza amostral, realizada no município de Belo Horizonte. Dados o seu caráter inédito e os resultados aqui apresentados, espera-se que o artigo, apesar de algumas limitações, traga novas contribuições ao campo.

A primeira parte do artigo apresenta o referencial teórico, abordando a literatura sobre empreendedorismo e marginalidade social, associada ao tema da estratificação e mobilidade social intergeracional (pais para filhos). Para efeito deste trabaIho, utiliza-se o conceito de empreendedor como definido por Gatner (1989): aquele que cria uma empresa. A segunda parte apresenta a metodologia utilizada para a pesquisa. Na terceira, são apresentados os principais resultados da pesquisa. Na con- 
clusão, são resgatados e destacados alguns pontos de maior interesse, para uma melhor compreensão do fenômeno. Salientase, aí, o papel do empreendedorismo como uma possível via de inserção e mobilidade social, sobretudo para indivíduos provenientes de estratos sócio-ocupacionais inferiores.

\section{REFERENCIAL TEÓRICO}

Muitos dos indivíduos que se tornam empreendedores buscam, por essa via, uma forma de inserção e mobilidade social. Esse fenômeno já fora observado por Simmel, um dos fundadores das ciências sociais. O autor (Simmel, 1986) dirigiu suas reflexões para a forma, ou seja, a "geometria" ou "gramática" da vida social. Segundo ele, a preocupação maior da sociologia deveria ser a associação, e não, exatamente, a sociedade. Nesse contexto, insere-se sua análise do "estrangeiro". Simmel (2005) vislumbra, no estrangeiro, o mercador, e, no mercador, o estrangeiro. 0 estrangeiro era um tipo particular de ator social, que se distinguia dos demais, não, exatamente, por critérios de classe ou religião, e, sim, pela sua forma de inserção social, explicitada pela natureza de seus laços de relacionamentos sociais. Era um ator, ao mesmo tempo, inserido em um dado grupo social, mas, também, um estranho naquele grupo. Consequentemente, era capaz de desempenhar atividades muitas vezes preteridas pela elite.

Observa-se, aí, o caráter ambíguo e desviante desse ator social, o que the confere maior amplitude de ações, podendo recorrer a meios não convencionais ou desejáveis pela elite. Hoselitz (1959) pondera que os homens de negócios e os mercadores representaram, durante o processo de desenvolvimento europeu, um tipo de desviante social. Seus papéis e atividades não eram considerados adequados para serem exercidos por membros das classes superiores. Posteriormente, Granovetter, 1983) também recorre aos conceitos de laços sociais (1983) e de inserção - embeddedness - (1985) para descrever o empreendedor. Ao analisar a sociologia econômica do empreendedor (2006), com base em evidências encontradas em grupos étnicos minoritários presentes em vários países - Estados Unidos, Filipinas, Tailândia, Java etc. - mostra como a natureza da inserção social desses indivíduos, na sociedade, tornava possível a criação de empreendimentos bem-sucedidos. Muitos autores enfocam o tema do empreendedorismo, a partir de observações em comunidades de imigrantes, enfatizando não apenas a importância dos laços sociais diferenciados (Portes, 1995), como, também, a importância do caráter desviante, marginal ou diferenciado de indivíduos que se tornam empreendedores (Light \& Rosenstein, 1995; Volery, 2007; Waldinger, Aldrich \& Ward,
1990). Como observado por Martinelli (2009, p. 219), “a questão das condições contextuais que produzem o empreendedorismo têm sido, tradicionalmente, abordada por alguns sociólogos em termos de desvio e marginalidade". Volery (2007, p. 31), ao analisar a história do empreendedorismo étnico nos Estados Unidos, salienta que teorias anteriores e proeminentes sugerem que tais fenômenos "são reações óbvias a limitações de oportunidades no mercado de trabalho, o que permanece verdadeiro hoje, em muitas instâncias". Tais limitações funcionariam, nesse caso, como estímulo para certos indivíduos buscarem o autoemprego, como mecanismo de inserção e mobilidade socioeconômica.

Apesar de a ampla maioria de estudos contemporâneos sobre exclusão social e empreendedorismo enfocar o tema dos imigrantes, proposições teóricas clássicas permitem estender tais reflexões para outros grupos ou segmentos sociais. Entre os pioneiros no tratamento de tal tema, situa-se Sombart (1928, 2001). Interessado em entender a dinâmica inicial do capitalismo, associa o empreendedor com o status de grupo social marginalizado. Para ele, a essência do espírito capitalista seria o desejo por afirmação e reconhecimento social, o que levaria o indivíduo a romper a tradição e a buscar novos caminhos. E tal evolução surgiu, segundo ele, como resultado de iniciativas, sobretudo, de três grupos sociais distintos, impedidos de ascender a postos públicos ou a outros canais de reconhecimento social: os estrangeiros, os heréticos e os judeus. Todos eles gozavam de possibilidades limitadas de mobilidade social, exceto para o desempenho de atividades econômicas. Como observado por Martinelli (2009), apesar de esse fenômeno ter se mostrado mais frequente nesses três tipos de grupos, a criatividade e a capacidade de romper valores tradicionais - características dos empreendedores modernos - podem estar presentes em qualquer povo, religião ou grupo social.

Hoselitz (1959), analisando os fatores contextuais que produzem o empreendedorismo, avança em sua concepção sobre o homem marginal. Segundo o autor, entre os condicionantes da marginalidade social, situar-se-iam fatores múltiplos, incluindo étnicos, religiosos, culturais, sociais e econômicos etc. Observa-se, nesse caso, uma ampliação do conceito de marginalidade ou exclusão social, que passa a englobar indivíduos inseridos em diferentes contextos sociais. Essa concepção torna-se, consequentemente, de maior utilidade para análises do fenômeno de marginalidade nas sociedades contemporâneas modernas, caracterizadas pela presença de um grande grau de diferenciação no próprio interior. Para Hoselitz (1959, p. 38), tal homem seria, sobretudo, aquele “dotado de uma posição ambígua sob um ponto de vista cultural, étnico ou social e, devido a isso, fortemente motivado a 
realizar ajustes em situação de mudança ou, eventualmente, no curso desse processo, desenvolver mudanças no comportamento social". Kilby (1971, p. 14) também enfatiza tal ponto, ao afirmar que a pessoa marginalizada, por possuir um posição social ambígua, "pode desenvolver inovações genuínas no comportamento social”. Observa Hoselitz (1959, p. 38) que o papel dos "indivíduos marginais em várias conquistas econômicas, em muitos países em desenvolvimento, manifestase ainda hoje", a exemplo da América Latina.

Hagen (1962) também comunga da percepção de Hoselitz. Para ele (1951 p. 127), “muitos membros da elite de sociedades tradicionais sentem repulsa em se associar a aspectos mais materiais da vida". Essa rejeição incluiria, segundo o autor, muitas vezes, o dia a dia na gestão de um negócio. Outros autores, porém, ao analisar a história do empreendedorismo em países da América Latina, apresentam, eventualmente, diferentes perspectivas. Dávila e Miller (2009), por exemplo, destaca a predominância das elites como atores empreendedoreschave no início do processo de desenvolvimento econômico de muitos países da região. No caso particular do Brasil, no entanto, o autor, destacando certa carência de estudos sobre o problema, reconhece a importância da imigração europeia. Esses imigrantes pertenciam a grupos sociais marginalizados. Ao mesmo tempo, observa o autor que, ainda nos dias de hoje, existiria, em vários desses países, a presença de um capitalismo de família ou do empreendedorismo como uma atividade ligada a famílias, independentemente do porte dos negócios.

Martinelli (2009, p. 224), referindo-se a críticas feitas às abordagens sociológicas que buscam explicar o empreendedorismo enfocando o contexto cultural - em particular, o tema da marginalidade social - acentua que o conceito de cultura, em muitos desses casos, costuma ser ampliado, para se incluírem, inclusive, as interações e redes sociais. Isso seria feito, segundo ele, sem uma maior preocupação com variáveis estruturais importantes, a exemplo da variável classe social. Esse desvio comprometeria as análises. 0 foco maior da preocupação de Martinelli é o fenômeno das interações sociais, como explorado por Granovetter $(1983,1985)$. Observa-se, no presente artigo, que não existe esse problema, visto que o tema da marginalidade social é abordado na perspectiva de categorias ou estratos sócio-ocupacionais. Ao mesmo tempo, busca-se aqui, também, ver algumas associações entre os estratos e as interações sociais dos indivíduos, na construção dos empreendimentos.

As abordagens sobre estratificação social variam segundo diferentes aparatos teóricos (Jannuzzi, 2003). Na visão marxista, existem duas classes antagônicas: proprietários e operários, definidas por meio da relação do indivíduo ou grupos com os meios de produção. Na tradição weberiana, existem três elementos que compõem um sistema de estratificação: classe (situação econômica no seio da sociedade, baseada no nascimento ou conquista individual), status (baseada no prestígio pessoal) e poder (habilidade para gerar obediência, apesar de eventuais resistências, a exemplo do poder burocrático). Weber vislumbrava a existência de quatro classes básicas: classe superior; empregados do colarinho-branco; pequena burguesia; classe trabalhadora.

Como observado por Jannuzzi (2003, p. 247), "a identificação da posição social dos indivíduos na sociedade, com a posição por eles desempenhada no mercado de trabalho, possui larga tradição nos estudos sobre estratificação social". Tanto a abordagem marxista - na qual as relações de classe são determinadas pelas relações de produção - quanto a abordagem weberiana - em que a estrutura de classe é consequência das desigualdades de oportunidades no mercado de trabalho - caminham nessa direção. Para os funcionalistas, na vertente de Talcott Parsons, a estratificação é necessária na sociedade moderna e funcionaria como um mecanismo que ajuda a estabilizar a estrutura social, na medida em que se baseia, crescentemente, em critérios universalistas de desempenho individual. Parsons (1970, 1974), ao analisar a sociedade americana, salienta que, devido a avanços da educação formal na alocação de status, o padrão da estratificação baseia-se, cada vez mais, em critérios de desempenho individual, em vez de parentesco.

As sociedades modernas convivem, em maior ou menor grau, com o fenômeno de mobilidade social. Ela é definida e mensurada, na literatura, de várias maneiras, por diferentes autores, dependendo, inclusive, de sua orientação teórica. De maneira geral, mobilidade social refere-se ao movimento, de um indivíduo ou grupo, de uma determinada posição social para outra. Como comentado por Figueiredo (2010, p. 2), enquanto os "sociólogos costumam observá-la como a transição entre classes de ocupação e/ou estratos sociais", os economistas dirigem sua atenção para a análise da renda, observando seja a transmissão de salários entre gerações (mobilidade intergeracional) ou, alternativamente, variações de renda de um mesmo indivíduo ao longo do tempo (mobilidade intrageracional). A mobilidade pode ser tanto vertical - quando ocorre entre níveis ou estratos socioeconômicos diferentes - ou horizontal quando ocorre de uma posição para outra, dotada do mesmo status socioeconômico. No contexto de abordagens sociológicas, temos, no Brasil, Pastore e Silva (1999). Como exemplo de abordagem de natureza econômica, temos Pochmann (2010).

Aliada à falta de consenso teórico existe, na visão de Figueiredo (2010), outra dificuldade. Pesquisas de campo que acompanham a evolução de famílias no Brasil não são muito comuns. A Pesquisa Nacional por Amostra de Domicílio (PNAD), 
realizada regularmente pelo Instituto Brasileiro de Geografia e Estatística (IBGE), uma das principais fontes de dados no País, apresenta algumas deficiências, que acabam por incidir sobre os resultados das pesquisas que utilizam esses dados para a análise da mobilidade social no Brasil. Existem outros problemas. Como observado por Goldthorpe e Jackson (2007, p. 525), “discussões sobre mobilidade social, motivadas por razões políticas, frequentemente revelam um ponto de vista inadequado, seja de problemas empíricos ou analíticos".

O tema da mobilidade social encontra-se intimamente relacionado ao tema da distribuição de rendas e oportunidades. Blander (2005) salientam que, quanto mais igualitário o país, maior a mobilidade social. O Brasil é considerado um país de grandes desigualdades de renda (Behraman et al. 2000). Para alguns autores, como Friedman (1962), a presença da desigualdade de renda, convivendo com certa rigidez no sistema de mobilidade social, geraria piores consequências para uma sociedade do que a presença da mesma desigualdade, aliada a certa flexibilidade no sistema de mobilidade social. Em sociedades mais democráticas, existiria relativamente maior chance da mobilidade vertical, caracterizando a presença de mais oportunidades.

Ferreira et al. (2012) observam que, apesar de ter ocorrido uma grande mobilidade ascendente em vários países da America Latina, nos últimos 15 anos, a mobilidade intergeracional continua estagnada. Figueiredo, Netto e Porto (2007) observam que, no período 1978-2003, o Brasil apresentou transformações expressivas na distribuição de renda, do ponto de vista estático. Os indicadores de desigualdade de renda, no entano, não conseguiram captar tais mudanças. Pochmann (2010) observa que, desde 2004, o Brasil encontra-se inserido em um novo padrão de mobilidade social, caracterizado pela presença de crescimento da renda nacional per capita, aliado à redução da desigualdade pessoal de renda, o que indicaria a presença de mobilidade social ascendente. Nos seus estudos, enfocando o período 1995/2005, Figueiredo (2010) mostra que o País apresentou uma baixa mobilidade intrageracional, o que sugere uma estrutura social relativamente rígida. Conclui que "o estrato de renda, na qual o indivíduo está inserido, será determinante para sua posição futura" (Figueiredo, 2010, p. 16). Estudo recém-publicado (Secretaria de Assuntos Estratégicos, 2013) mostra que o Brasil vem apresentando, nos últimos anos, um fenômeno de mobilidade social, sobretudo nos estratos mais baixos da população. Tal fenômeno não poderia ser desvinculado do empreendedorismo.

Vários estudos procuram identificar se a origem familiar (situação dos pais) possuiria forte influência sobre o sucesso dos filhos no mercado de trabalho. Corak (2006) observa que, nos Estados Unidos, metade das crianças nascidas em lares pobres tornam-se adultos pobres. Ao mesmo tempo, crianças ricas tendem a tornar-se adultos ricos. Sorokin (2001) observa que, no caso do Brasil, continua a existir uma transmissão hereditária, ou seja, a ocupação dos pais continuaria influenciando a realização de status dos filhos. Helal (2008), ao analisar o padrão de estratificação social encontrado em certos segmentos ocupacionais no País, observa a capacidade da elite de se reproduzir, por meio da educação casada com influência familiares. Dessa maneira, ela seria capaz de garantir, aos seus descendentes, certos privilégios, inclusive em posições-chave do setor público. Ribeiro (2007) constatou que as pessoas provenientes de posições de maior prestígio social continuavam a ter melhores chances de ocupar novas posições, igualmente dotadas de prestígio.

Embora existam pesquisas de campo sobre mobilidade social, inclusive no Brasil, nota-se que, sobre o tema específico de interesse do presente trabalho - ou seja, empreendedorismo, exclusão social e mobilidade - distinguem-se, na literatura, dois tipos de pesquisas de maior interesse. 0 primeiro, mais comum e de interesse indireto, busca, principalmente por meio de pesquisas qualitativas, avaliar o processo de inserção social de certas minorias, especialmente imigrantes, a exemplo de Granovetter (2003), Portes (1995), Pereira (1964) ou Martes e Rodriguez (2004). O segundo, mais raro e de maior interesse, no presente caso, busca analisar o fenômeno de mobilidade social de segmentos maiores da população de empreendedores, a exemplo de Harris (1971), que realizou uma pesquisa quantitativa, de natureza amostral, envolvendo 250 empreendedores na Nigéria. O autor conclui (Harris, 1971, p. 336) que a "atividade empreendedora tem sido uma avenida de mobilidade social vertical para muitos empreendedores". Desconhecemos pesquisas semelhantes a essa, realizadas no País. Estudo recente divulgado (Secretaria de Assuntos Estratégicos, 2013) aborda, por meio de dados secundários, o tema de interesse, enfocando os "novos" empreendedores que ingressam na "nova" classe média. Seu conceito de empreendedor, no entanto, destoa do nosso, ao incorporar, sobretudo, autônomos e trabalhadores por conta própria.

\section{REFERENCIAL METODOLÓGICO}

A pesquisa de campo, concluída em 2011, foi elaborada com base em uma amostra representativa da população de interesse do presente trabalho. A amostra foi composta por 100 empreendedores do setor da indústria de transformação, localizados em Belo Horizonte, que criaram suas empresas e que permanece- 
ram à frente de seus empreendimentos. 0 parque produtivo do município é composto, em sua maioria, por empresas de setores tradicionais, como confecções, alimentação, metalurgia etc. A pesquisa apresenta um nível de confiança de 95,5\% e um erro amostral de 10 pontos percentuais (Tagliacarne, 1974). A amostra, de natureza aleatória simples, sem reposição, foi extraída de um universo composto por 4.100 empreendedores industriais, integrantes do cadastro de empresas da Federação das Indústrias de Minas Gerais (FIEMG). Um dos maiores desafios na realização de pesquisas de campo no Brasil, com base em amostras de universos empresariais extensos, é, exatamente, o acesso a cadastros contendo essa população. Os cadastros existentes ou não se encontram disponíveis (a exemplo do cadastro de contribuintes, pessoa jurídica, da Secretaria da Receita Federal) ou não são atualizados (cadastros das Juntas Comerciais/DNRC, com grande parcela de empresas já extintas, mas que não deram baixa). A presente pesquisa contornou esses problemas por meio de uma escolha mais precisa do universo ou segmento empresarial de interesse.

Pode-se estimar, com base em dados do Serviço Brasileiro de Apoio às Micro e Pequenas Empresas (Sebrae) e do Departamento Intersindical de Estatística e Estudos Socioeconômicos (Dieese) (2011), que as empresas cadastradas, afiliadas à FIEMG, representam cerca de $50 \%$ do total de empresas industriais existentes no município. A maior parte dos empreendedores pesquisados ( $99 \%$ do total) era detentora de micro e pequenas empresas. Essa parcela coincide com o total de micro e pequenas empresas em nível nacional (Sebrae \& Dieese, 2011). Os dados da pesquisa foram coletados por meio de questionários estruturados, complementados por entrevistas. As entrevistas foram realizadas com o propósito de captar casos mais interessantes ou emblemáticos de trajetórias empreendedoras. Por questão de enfoque e, também, por limitação de espaço no presente artigo, exploram-se, sobretudo, os dados quantitativos. Acessoriamente, são inseridos alguns resultados das entrevistas, com o propósito de enriquecer alguns comentários.

Os dados, após coletados, foram processados em dois momentos distintos. Em um primeiro momento, procurou-se identificar tanto o estrato socioeconômico de origem dos empreendedores (famílias de origem/pais) quanto a situação corrente do empreendedor. Para a identificação de suas respectivas famílias de origem, trabalhou-se com dados, fornecidos diretamente pelos empreendedores, sobre seus pais, incluindo formação escolar, ocupação prévia de pai e mãe e condição financeira familiar. Para se identificar o estrato corrente dos empreendedores, trabalhou-se com dados, também por eles fornecidos, sobre suas respectivas formações escolares, condições financeiras e natureza dos seus empreendimentos. Para a cole- ta dos dados, utilizou-se um questionário estruturado, contendo um conjunto de questões. No caso da formação escolar, foi usada uma grade, contendo diferentes níveis escolares alternativos, incluindo: i) sem formação; ii) primário incompleto; iii) primário completo e, assim, sucessivamente. No caso em que foi assinalado um curso técnico ou um curso superior, o entrevistado foi solicitado a especificar a área.

Para a identificação da ocupação dos pais, foi utilizado um conjunto de opções alternativas, incluindo: i) empregado de empresa (no caso, solicitava-se que fosse especificada a natureza do trabalho, além do tipo/porte da empresa); ii) funcionário público (com especificação de função/tipo de entidade pública); iii) empreendedor (com especificação de ramo/número de empregados); iv) profissional liberal (especificação do serviço/área); v) professor (especificação de nível) vi) fazendeiro; vii) sitiante; viii) trabalhador manual (especificação) etc. Nesse conjunto, foi inserida, ao final, a opção outras ocupações, com o propósito de captar ocupações não mencionadas previamente. Para se identificar a condição financeira dos pais, trabalhouse com um conjunto de diferentes opções, incluindo: i) situação financeira muito difícil; ii) razoavelmente difícil; iii) confortável/ boa; iv) muito boa; v) excelente. Já no caso das condições financeiras do próprio empreendedor, trabalhou-se com as alternativas acima, acrescidas de questões sobre a natureza do empreendimento, incluindo: setor de atividades, data de criação, número de empregados iniciais e correntes, extensão do mercado atual (local/bairro, cidade, estado, país). o questionário, após preenchido, foi complementado por informações adicionais, coletadas por meio de entrevistas.

Com base no conjunto dos dados coletados no questionário, foram identificados tanto os estratos socioeconômicos correntes dos empreendedores como de seus respectivos pais (famílias de origem). A comparação entre eles permitiu identificar o padrão de mobilidade social intergeracional incorrido (grupo ocupacional de status de cada empreendedor em relação ao de seus pais). Embora seja um fenômeno universal, a estraficação social apresenta grandes variações locais. Os critérios de definição de estratificação social são dinâmicos e devem ser elaborados com base em dados empíricos, associados à situação concreta de uma dada sociedade (Jannuzzi, 2003). A literatura vem demonstrando que existem controvérsias sobre quais seriam os fatores a serem considerados, em uma dada sociedade, para aferição dos estratos sociais (Crompton, 1994; Erikson \& Goldthorpe, 1993).

No Brasil, as classificações mais comuns são baseadas em renda familiar (a exemplo da PNAD/IBGE) ou critérios baseados no poder de consumo. Para Jannuzzi (2003), existe, nos estudos acadêmicos realizados no País, uma certa pri- 
mazia de critérios geográficos e de poder de consumo. Tais critérios, sobretudo no contexto de baixa inflação, queda nas taxas reais de juros e redução dos preços relativos dos eletrodomésticos, perdeu grande parte de sua capacidade explicativa. É o caso de critérios classificatórios baseados na posse de bens duráveis. Ao mesmo tempo, salienta o autor que os sistemas classificatórios, baseados na posição dos indivíduos no mercado de trabalho - representando a sua posição na pirâmede social - embora encontrem ampla aceitação em países como os EUA, não são difundidos no Brasil.
Jannuzzi propõe, como alternativa para o caso brasileiro, a utilização de uma escala sócio-ocupacional, que teria condições de captar diferenciações relevantes no que diz respeito a rendimentos, escolaridade, qualidade e segurança no trabalho (Quadro 1). Como comentado pelo autor (Jannuzzi, 2003, p. 252), tal estratificação ou segmentação socioeconômica equivaleria a uma "subdivisão da população segundo grupos ocupacionais de status socioeconômico diferenciado". Essa escala, com algumas pequenas adaptações, foi utilizada na presente pesquisa.

\section{Quadro 1. Escala socioeconômica para as ocupações brasileiras}

\begin{tabular}{|c|c|c|c|}
\hline Categorias & Conceito & Ocupações típicas & Exemplos de ocupações \\
\hline 1. alta & $\begin{array}{l}\text { Renda elevada, escolaridade mínima } \\
16 \text { anos, alta qualidade de emprego/ } \\
\text { ocupação }\end{array}$ & $\begin{array}{l}\text { Profissionais liberais altamente } \\
\text { qualificados, grandes proprietários, } \\
\text { quadros superiores de grandes } \\
\text { empresas e da administração pública }\end{array}$ & $\begin{array}{l}\text { Empresários, executivos e } \\
\text { supervisores de empresas maiores, } \\
\text { juízes, promotores, professores de } \\
\text { curso superior, médicos e advogados } \\
\text { qualificados etc. }\end{array}$ \\
\hline 2. média-alta & $\begin{array}{l}\text { Renda mais baixa, escolaridade um } \\
\text { pouco mais baixa, pequeno risco de } \\
\text { desemprego/ocupação }\end{array}$ & $\begin{array}{l}\text { Quadros intermediários qualificados } \\
\text { de empresas, funcionários públicos, } \\
\text { empreendedores de porte médio }\end{array}$ & $\begin{array}{l}\text { Contadores, professores, corretores, } \\
\text { sócios proprietários de médias } \\
\text { empresas etc. }\end{array}$ \\
\hline 3. média & $\begin{array}{l}\text { Certa qualificação profissional, } \\
\text { emprego mais precário }\end{array}$ & $\begin{array}{l}\text { Ocupações no comércio, serviço e } \\
\text { postos qualificados na indústria, } \\
\text { técnicos de nível médio, operários } \\
\text { qualificados da indústria, prestadores } \\
\text { de serviços, trabalhadores manuais } \\
\text { qualificados, pequenos empresários }\end{array}$ & $\begin{array}{l}\text { Técnicos de contabilidade, torneiros } \\
\text { mecânicos, eletricistas, comerciantes, } \\
\text { donos de pequenas confecções etc. }\end{array}$ \\
\hline 4. média-baixa & $\begin{array}{l}\text { Baixa qualificação, emprego precário, } \\
\text { risco elevado de desemprego }\end{array}$ & $\begin{array}{l}\text { Empregados de baixa qualificação } \\
\text { nos serviços, construção civil } \\
\text { e indústria tradicional, donos } \\
\text { de microempresas de setores } \\
\text { tradicionais }\end{array}$ & $\begin{array}{l}\text { Pedreiros, pintores, vigias, garçons, } \\
\text { porteiros, donos de serralherias etc. }\end{array}$ \\
\hline 5. baixa & $\begin{array}{l}\text { Ausência de qualificação, alta } \\
\text { precariedade de emprego/ocupação }\end{array}$ & $\begin{array}{l}\text { Trabalhadores rurais ou autônomos } \\
\text { (meeiros), trabalhadores urbanos de } \\
\text { baixo status }\end{array}$ & $\begin{array}{l}\text { Serventes de pedreiro, empregadas } \\
\text { domésticas, lixeiros etc. }\end{array}$ \\
\hline
\end{tabular}

Fonte: Adaptado da tabela de estratificação sócio-ocupacional de Jannuzzi (2003), que utiliza, para a especificação das categorias, proposições de Silva e de Goldthorpe (1992) e dados dos Censos Demográficos e PNAD/IBGE.

A pesquisa encontrou quatro estratos ou categorias de origem dos empreendedores (situação dos pais/famílias), incluindo: médio-alto, médio, médio-baixo, baixo. Foi identificado apenas um caso no estrato médio-alto. 0 estrato alto não foi encontrado na presente pesquisa. A análise da situação corrente dos empreendedores, por sua vez, permitiu enquadrá-los em quatro estratos distintos: alto, médio-alto, médio, médio -baixo. A comparação entre as duas gerações - por um lado, a situação familiar (pais), e, por outro, a situação corrente do empreendedor - permitiu a identificação da mobilidade social intergeracional.
Numa segunda etapa, com os empreendedores devidamente enquadrados em seus respectivos estratos de origem (família/pais), foi possível dar continuidade ao processamento dos demais dados de interesse (a exemplo das motivações para empreender). Eles foram tabulados, fazendo-se uma distinção entre os três principais estratos de origem dos empreendedores (médio, médio-baixo, baixo). Múltiplos e, muitas vezes, interconectados, podem ser os motivos que levam uma pessoa a criar uma empresa. Como salientado por Friedman (1986), o empreendedorismo pode ocorrer em função de estímulo ambiental, oportunidade e necessidade, podendo, consequentemen- 
te, vir como resultante de vários motivos intervenientes. Tais motivos podem variar, indo desde a identificação de uma oportunidade de negócios, considerada lucrativa, até a pressão do desemprego. Na presente pesquisa, trabalhou-se um conjunto de diferentes motivos, incluindo: i) facilidade de usar os relacionamentos; ii) possibilidade de usar influência da família; iii) desejo de ter o seu próprio negócio/tornar-se independente; iv) necessidade de ampliar a renda; v) necessidade de dar ocupação a outros membros da família; vi) insatisfação com o emprego; vii) desemprego; viii) identificação de uma oportunidade de negócios; ix) outros (com especificação). Os empreendedores foram solicitados a indicar os motivos mais importantes, intervenientes nos seus processos de criação dos empreendimentos. A questão permitia múltiplas respostas.

Durante o processamento dos dados, buscou-se avaliar se a variável independente (estrato/categoria sócio-ocupacional de origem do indivíduo) encontrava-se associada a variáveis dependentes (exemplo: motivos que levaram à criação do empreendimento). Para verificar a presença (ou ausência) de associações entre as variáveis de interesse, foi utilizado, na análise dos dados, o teste do Qui Quadrado. Nesse caso, foram considerados níveis de significância iguais ou inferiores a 0,050 (não significante acima desse valor). Alguns dos resultados dos testes são aqui apresentados.

\section{RESULTADOS ENCONTRADOS}

Analisando-se a posição atual dos empreendedores (estratificação atual), verifica-se que a maioria deles pertence, atualmente, à categoria sócio-ocupacional média ( $67 \%$ deles). Em sua maioria (85\%), porém, originaram-se dos estratos médio e médio-baixo (estratificação original), ou seja, não foram originários da elite. Comparando-se a posição passada dos empreendedores com suas respectivas posições correntes, observa-se o padrão incorrido de mobilidade. Quando um empreendedor permanece no mesmo estrato de seus pais, pode ter ocorrido ou não mobilidade social. Se ele permaneceu na mesma categoria ocupacional de seus pais, não se registrou a presença de mobilidade. Foi o caso, por exemplo, de um indivíduo, filho de um empreendedor (no caso, um comerciante), que decidiu também se tornar empreendedor (abrindo uma empresa de esquadrias de alumínio), onde manteve padrão socioeconômico semelhante ao de seus pais.

Alternativamente, se o indivíduo mudou de ocupação, mas não de estrato, registra-se a presença de mobilidade horizontal. Foi o caso de um empreendedor, hoje sócio proprietário de uma empresa que produz artefatos de couro, cujo pai foi funcionário público. Quando um empreendedor apresenta mudança de estrato sócio-ocupacional - ou seja, mobilidade vertical - isso quer dizer que houve mudança no seu status socioeconômico, em relação ao de seus pais. Foi o caso de um entrevistado, hoje dono de uma empresa de estofados, cujo pai era servente de pedreiro. Nesse caso, ele não apenas mudou de ocupação como, também, apresentou ascensão social.

Para uma parcela significativa dos empreendedores ( $42 \%$ do total), a situação financeira na família de origem (pais) foi considerada difícil. Essa parcela varia bastante segundo os estratos: $18 \%$ no caso dos remanescentes do estrato médio, $54 \%$ do estrato médio-baixo e $86 \%$ no estrato baixo. Como esperado, existe uma associação entre o estrato de origem dos pais e as dificuldades financeiras enfrentadas pela família de origem (teste do quiquadrado apresentou significância menor do que o,001).

Observando-se a posição passada dos empreendedores, constata-se que 44 deles vieram do estrato médio, 41 , do estrato médio-baixo, 14, do baixo e um, do médio-alto. Dos 44 empreendedores que se originaram do estrato médio (ou seja, com pais dotados de qualificação profissional, com ocupações relativamente estáveis - a exemplo de alguns empresários, funcionários públicos de quadros intermediários etc.), 40 permaneceram no mesmo estrato dos pais, um ascendeu ao estrato médio-alto, um ao estrato alto, enquanto dois regrediram ao estrato médio-baixo. Observa-se que, nesse contexto, o resultado da mobilidade foi nulo. Já no caso dos 41 empreendedores remanescentes do estrato médio-baixo (pais com menor qualificação e maior risco de desemprego, realizando atividades manuais, tais como sitiantes, motoristas, taxistas etc.), 23 aí permaneceram (como donos de pequenas marcenarias, serralherias, estofadores etc.), enquanto 18 ascenderam ao estrato médio, ou seja, ocorreu mobilidade intergeracional em $44 \%$ desse total.

Entre os 14 empreendedores remanescentes do estrato baixo (provenientes de famílias com pais sem qualificação e empregos muito precários, tais como autônomos sem qualificação, trabalhadores desqualificados da construção civil etc.), nove ascenderam ao estrato médio e cinco, ao estrato médio -baixo. Registra-se mobilidade em 100\% dos casos. Dos 100 empreendedores pesquisados, 67 deles posicionam-se, atualmente, no estrato médio, 30, no médio-baixo, dois, no médio alto, e um, no alto.

Pela análise dos dados, constata-se que os percentuais de ascensão sócio-ocupacional, por estrato, foram, respectivamente, de o\% no caso de empreendedores originários do estrato médio-alto, de $2,5 \%$ no caso dos remanescentes do estrato médio, de $44 \%$ no caso dos originários do médio-baixo e 
de $100 \%$ para aqueles provenientes do estrato baixo (Sig. de 0,000 ). Tais dados indicam que as chances de mobilidade encontram-se associadas ao estrato de origem do indivíduo. Conclui-se, pela análise dos dados, que, no caso da população analisada, existe uma associação entre o estrato de origem do empreendedor e a presença - maior ou menor - de mobilidade social ascendente.

A maior parte dos indivíduos pesquisados, em todos os estratos, foi compelida ao empreendedorismo sem vontade: $70 \%$ deles pretendiam/almejavam, originalmente, ter um bom emprego (antes de abrirem suas empresas). Gostariam de fazer carreiras em empresas onde já trabalhavam ou em boas organizações. Por uma razão ou outra, porém, foram compelidos ou motivados a abrir uma empresa. Foi o caso de um dos entrevistados (aqui designado empreendedor 1), hoje sócio proprietário de uma empresa de confecções, com 19 empregados. Seu sonho, aos 18 anos, era realizar um curso superior e profissionalizar-se na área, mas foi surpreendido por uma reviravolta, quando sua família, de classe média, enfrentou um processo de falência da empresa de propriedade de seu pai. Narra o entrevistado que teve que deixar os estudos para um segundo plano e começou, então, a trabalhar em uma empresa ligada à área de confecção. Quando, em 2002, essa empresa foi fechada, percebeu que não possuía muitas alternativas de carreira. Sem formação superior, sem muito capital e com relacionamentos mais limitados à sua área de trabalho, viu-se, então, compelido a criar seu próprio empreendimento. E o fez na mesma área de seu antigo trabalho.

Analisando-se alguns do fatores ou motivos que levaram os indivíduos a abrir uma empresa, observa-se que existem variações entre os estratos. Para $73 \%$ do total de empreendedores pesquisados, remanescentes do estrato baixo médio, o fator “identificação de uma oportunidade de negócio” foi considerado importante. Tal parcela cai para $43 \%$ no caso dos originários do estrato baixo (sig. de 0,039). Ao mesmo tempo, empreendedores remanescentes do estrato baixo são relativamente mais sensíveis a fatores associados a emprego e à necessidade de aumentar a renda. É assim que $72 \%$ deles buscaram aumentar a renda (contra 58\% dos remanescentes do estrato médio); $36 \%$ deles necessitavam dar ocupação a outros membros da família (contra $10 \%$ originários do extrato médio); $29 \%$ encontravam-se desempregados (contra $7 \%$ no caso do extrato médio).

Entre os empreendedores entrevistados, originários do estrato baixo, situa-se o empreendedor 2, atualmente dono de uma marcenaria e residente em um bairro de classe média. Sua empresa possui oito empregados e atende clientes localizados em vários pontos da cidade. É casado e pais de três fiIhos. Seu patamar de vida, no entanto, destoa bastante do que conheceu antes. Seu pai era lavrador e a família, composta por muitos irmãos, passou por momentos de grandes dificuldades. Ainda jovem, o entrevistado foi tentar a vida na capital, onde, depois de outras experiências, começou a trabalhar em uma pequena marcenaria. Daí passou para outra. Teve oportunidade de aprender o oficio e conhecer alguns clientes e fornecedores de seu patrão. Com o tempo, ganhou experiência. Pressionado por problemas financeiros, resolveu, em 1989, deixar o emprego e trabalhar por conta própria. Como seus clientes começaram a aumentar e ele necessitava de mão de obra, iniciou a criação de um empreendimento, formalizado em 1997. Sua empresa vem conseguindo manter-se no mercado, apesar da grande concorrência.

A pesquisa constatou que ocorreu melhoria na escolaridade dos empreendedores, em relação à de seus respectivos pais. Enquanto $87 \%$ dos pais dos empreendedores não possuíam curso superior, tal proporção cai, dependendo do estrato dos empreendedores pesquisados: é de $55 \%$ nos remanescentes do estrato médio, de $61 \%$ no caso dos originários do estrato médio-baixo, e de 93\% no caso do estrato baixo (sig de 0,039). Além de possuírem maior nível de escolaridade e de estarem menos sujeitos à pressão do desemprego e da necessidade de aumentar a renda, empreendedores originários dos estratos superiores parecem contar com vantagens de relacionamentos.

É isso que $22 \%$ dos empreendedores que vieram do estrato médio alegaram, entre os motivos para a criação da empresa: a possibilidade de utilizar a influência da família (contra $14 \%$ no estrato baixo). Nesse contexto, insere-se o caso do empreendedor 3, que cresceu em um bairro de classe média. Seu pai era dono de uma mercearia, de onde tirava o sustento da família. Alguns de seus tios eram, também, donos de pequenos negócios. 0 entrevistado, quando mais jovem, conseguiu, por meio de indicações de um amigo da família, ingressar em uma grande empresa local. Posteriormente, ao concluir seu curso superior, permaneceu nessa empresa, onde, por algum tempo, fez carreira. Seus conhecimentos e seus contatos, adquiridos durante seu trabalho, somados a contatos no seio familiar, permitiram-lhe vislumbrar oportunidades de negócios. Decidiu, finalmente, explorar uma delas. Em 2005 abriu, então, uma empresa no setor de processamento de mármores e granitos. Sua empresa prosperou e, junto com ela, seu padrão de vida, que ele considera hoje muito confortável.

\section{CONSIDERAÇÕES FINAIS}

Os resultados obtidos sugerem que, pelo menos no contexto do universo pesquisado, a iniciativa empreendedora não cons- 
tituiu, em geral, um fenômeno originário da elite. Foi, sobretudo, derivada dos estratos médio e médio-baixo da população ( $55 \%$ do total). Observa-se, também, que o empreendedorismo não parece ser, inicialmente, muito procurado ou valorizado como uma primeira opção de carreira e profissão, como atestado por $70 \%$ dos empreendedores pesquisados. A falta de interesse, pelo menos inicial, pela via do empreendedorismo, aliada a informações sobre o estrato sócio-ocupacional de origem dos empreendedores, atestaria proposições de Hagen (1962), sobre uma certa rejeição que membros da elite, eventualmente, teriam em se associar ao dia a dia da gestão de negócios; ou de Volery (2007), que vê no empreendedorismo uma forma de autoemprego; ou de Hoselitz (1959), que observou que indivíduos provenientes de camadas mais marginalizadas ou mais vulneráveis apresentam, em geral, maiores chances de tornarem-se empreendedores. Tais indivíduos, segundo autores como Volery (2007), Chen e Tan (2008), Jones e Wadhwani (2006), ao se defrontarem, por um motivo ou outro, com limitações impostas à entrada em carreiras mais tradicionais, dirigem-se ao empreendedorismo. Esse foi o caso, por exemplo, do empreendedor 1, que se viu compelido ao empreendedorismo, por falta de outras opções consideradas, naquele momento, mais atraentes. Tais evidências contrariam proposições de Martinelli (2009). Mesmo em uma sociedade moderna, como é o caso de Belo Horizonte, os dados sugerem que, no segmento pesquisado, o ímpeto empreendedor pode não se originar, prioritariamente, da elite. Esse fenômeno existe quando a sociedade não imputa grande valor à função empreendedora, preferindo que os seus filhos, mais bem formados em termos educacionais, sigam carreiras mais convencionais.

A escolaridade relativamente baixa de seus pais e, em certa medida, dos próprios empreendedores poderia ajudar a explicar eventuais limitações de acesso a outras alternativas, por eles inicialmente almejadas - como obter bons empregos ou progredir como empregados em empresas onde já trabalhavam. Evidências da pesquisa, embora limitadas a certo universo, poderiam respaldar proposições de Ramos e Vieira (2001), sobre a atual importância da escolaridade, para a vida e a carreira. Privados de um dos pré-requisitos para uma carreira desejada dentro de uma organização, recorrem, muitas vezes, ao empreendedorismo, como uma possível via de inserção social. Cita-se, aqui, novamente, o caso do empreendedor 1 , que, segundo sua própria avaliação, teve que recorrer ao empreendedorismo.

Além de apresentarem uma escolaridade relativamente mais baixa, indivíduos remanescentes de estratos inferiores parecem contar, relativamente menos, com a influência dos laços familiares para sustentação de suas iniciativas (poucos deles citaram, entre os motivos para a criação da empresa, também a possibilidade de usar laços familiares). Esse último ponto chama a atenção para proposições de Martinelli (2009), que, em sintonia com Granovetter (1985), enfatiza a necessidade de se incorporar, nas análises sobre fenômenos de natureza econômica, a dimensão das interações sociais. Analisando-se situações aqui narradas (empreendedores 2 e 3), observa-se que, em ambos os casos, suas redes de contatos foram importantes, como plataformas para viabilizar seus empreendimentos. Mas, enquanto o empreendedor inserido no estrato baixo (empreendedor 2) foi compelido ao empreendedorismo por pressões de natureza financeira e recorreu, então, a clientes de seu antigo patrão, o empreendedor inserido no estrato médio (empreendedor 3) foi compelido ao empreendedorismo porque, por meio dos laços familiares, pessoais e profissionais, identificou uma oportunidade, que decidiu explorar, criando uma empresa. Da mesma maneira que o empreendedor 2, o empreendedor 1 não estava, inicialmente, interessado em abrir uma empresa. Em ambos os casos, submetidos a pressões de natureza financeira, não conseguiram vislumbrar outras alternativas de carreira.

Entre os pais dos empreendedores, encontram-se professores, funcionários públicos, empregados de pequenas empresas, profissionais liberais, operários especializados, marceneiros, motoristas, metalúrgicos, vendedores, lavradores, autônomos, empreendedores etc. A parcela constituída por empreendedores, no segmento pesquisado, é significativa: $32 \%$ do total. Esses dados, no contexto do universo pesquisado, chamam a atenção para três pontos, em particular. Em primeiro lugar, para proposições de Sorokin (2001) - sobre a influência que a ocupação dos pais exerceria sobre a ocupação futura dos filhos. Parece que famílias de empreendedores podem, com maior frequência, gerar filhos também empreendedores. Em segundo lugar, para proposições de Dávilla (2009), que destaca as vinculações existentes entre empreendedorismo e família. De fato, no segmento pesquisado, parece que famílias empreendedoras apresentam maior propensão a gerar filhos também empreendedores. Quando o empreendedor 3 fundou sua empresa, ele se sentia muito confortável para negociar com clientes e fornecedores. Sua criação, no contexto de uma família de empreendedores, parece ter-lhe dado uma habilidade especial, inclusive para comprar e vender. Essas hipóteses, no entanto, devem ser mais bem testadas em novas pesquisas. Em terceiro lugar, observando-se a parcela restante de empreendedores originários de pais que não o eram $(68 \%$ com outras ocupações), pode-se concluir que o empreendedorismo apresenta-se, muitas vezes, como uma via real de mudanças e transformações sócio-ocupacionais. 
A dinâmica entre os fenômenos de reprodução e de mudança torna-se mais clara quando se analisa o estrato sócio-ocupacional dos indivíduos. A pesquisa constatou que vem ocorrendo mobilidade intergeracional no segmento de empreendedores, seja esta de natureza horizontal (mudança da ocupação do filho em relação à dos pais), seja de natureza vertical. Sobre essa última, observa-se que, quanto mais elevado o estrato sócio-ocupacional do indivíduo, mais o empreendedorismo tende a funcionar como uma via de preservação do mesmo estrato dos pais. Por outro lado, quanto mais baixo o estrato sócio-ocupacional do indivíduo, maior a chance de o empreendedorismo constituir um mecanismo de mudança de estrato. Tal fato relativizaria proposições de que a origem social do indivíduo - se mais pobre ou rico condicionaria o seu futuro (Corak, 2006). Os resultados sugerem que a via do empreendedorismo poderia, eventualmente, ajudar na democratização de uma sociedade, reduzindo suas distorções, na linha comentada por Friedman (1962). Isso seria particularmente importante no Brasil, país caracterizado por elevado nível de desigualdade de renda (Skekely et al. 2000), convivendo com certa rigidez nos processos de mobilidade social intergeracional (Ferreira et al., 2012; Figueiredo, 2010), em que pesem avanços recentes nesse campo.

Embora a natureza do universo de interesse desta pesquisa impeça a generalização de seus resultados para outros segmentos empresariais - incluindo o setor industrial de Belo Horizonte ou, mesmo, os setores de serviços ou comércio essa mesma natureza traz alguns benefícios para futuros pesquisadores, interessados em estudos comparativos envolvendo diferentes regiões. É possível recorrer a amostras representativas de universos ou populações semelhantes ao aqui enfocado. Existe, em todos os estados do País, a presença de uma federação de empresas, agregando parcela significativa do universo de empresas aí existentes. Ao mesmo tempo, dada a importância econômica, política e institucional de algumas dessas entidades, tanto em nível local quanto nacional, seria importante, por si só, conhecer a natureza e origem dos empreendedores a elas afiliados. Alguns deles estão, certamente, posicionados entre a elite produtiva do País. A presente pesquisa, apesar de limitações, fornece referências, inclusive de ordem metodológica, para futuras investigações. No contexto das atuais reflexões, residiria uma questão de particular interesse, que necessitaria ser abordada em novas pesquisas. Trata-se de saber se o Brasil constitui-se, de fato, em um país de empreendedores, como vem sendo divulgado, ou, alternativamente, se seria um país onde a elite, sobretudo não ligada ao empreendedorismo, continua valorizando as funções de Estado e as carreiras em grandes corporações. A realidade, hoje desconhecida, vai impactar o futuro do País.

\section{Nota de agradecimento}

A autora agradece o apoio do CNPq ao projeto, bem como as contribuições do Prof. Philippe Steiner/ Université de Paris Sorbonne ao artigo.

\section{REFERÊNCIAS}

Aldridge, H, Kenway, P, Maclness, T, \& Parckh, A. (2012). Monitoring poverty and social exclusion 2012. York: Joseph Roluntree Foundation.

Auer, P, Efendioglu, U, \& Leschke, J. (2005). Active labour market policies around the world: coping with consequences of globalization. Genebra: OIT.

Beloque, L. D. (2007). A cor do "trabalho informal": uma perspectiva de análise das atividades "informais". Tese de doutorado, PUC-SP, São Paulo.

Blanden, J. (2005). International evidence on intergeneration mobility. Annual Conference, London School of Economics, London.

Chen, W, \& Tan, J. (2008). Roots and wings: globalized networks and transnational entrpreneurship, Best Paper Proceedings, Academy of Management, Anaheim, CA.

Corak, M. (2006). Do poor children become poor adults? Lessons from a cross-country comparison of generational earnings mobility. Research on Economic Inequality, 13(1), 143-188.

Crompton, R. (1994). Clase y estratificación: una introducción a los debates actuales. Madrid: Tecnos.

Dávila, C., \& Miller. R. (1999). Business history in Latin America: the experience of seven countries. Liverpool: Liverpool University Press.

DeVerteuil, G. (2009). Inequality. International Encyclopedia of Human Geography. Kidlington, UK, Elsevie (pp. 433-445).

Erikson, R, \& Goldthorpe, J. (1993). The constant flux: a study of class mobility in industrial societies. Oxford: Clarendon Press.

Ferreira, F. H. G, Messina, J, Rigolini, J, López-Calva, L. F, Lugo, M. A, \& Vakis, R. (2012). Economic mobility and the rise of Latin American middle class. Washington: World Bank.

Figueiredo, E. (setembro/dezembro 2010). Mobilidade intergeracional de renda no Brasil. Nova Economia, 20 (3), 427- 455

Figueiredo, E, Netto, J., \& Porto, S. (2007). Distribuição, mobilidade e polarização de renda no Brasil: 1987 a 2003. RBE-Revista Brasileira de Economia, 61(1), 7-32.

Friedman, M. (1962). Capitalism and freedom. Chicago: University of Chicago Press.

Friedman, R. E. (1986). Entrepreneurial renewal in the industrial city. Annals of the American academic political science, 488, 35-46.

Gatner, W. B. (1989). "Who is the entrepreneur?" is the wrong question. Entrepreneurship theory and practice. Summer edition, 47-68.

Goldthorpe, J. H, \& Jackson, M. (2007). Intergenerational class mobility in contemporary Britain: political concerns and empirical findings. The British Journal of Sociology, 58(4), 525-546.

Goldthorpe, J.H. Social mobility and class structure in modern britain. New York: Oxford University Press, 1992

Granovetter, M. (1983). The strength of weak ties: a network theory revisited. Sociological Theory, 1, 201-233.

Granovetter, M. (1985). Economic action and social structure: the problem of embeddedness. American Journal of Sociology, 91(3), 481-510. 
Granovetter, M. (2003). La sociologie économique des enterprises e des entrepreneurs. Terrain \& Travail, 4, 167-206.

Hagen, E. E. (1962). How economic growth begin: a theory of social change. In E. E. Hagen (Ed.). On the theory of social changes: how economic growth begins. Hommewood, IL: Dorsey Press.

Harris, J. R. (1971). Nigerian entrepreneurship in industry. In P. Kilby. Entrepreneurship and economic development. (pp. 333-356). New York: The Free Press.

Helal, D. (2008). A dinâmica da estratificação social no setor público brasileiro: meritocracia ou reprodução social? Tese de doutorado, Belo Horizonte: UFMG

Hoselitz, B. F. (1951). The early history of entrepreneurial theory. Explorations in entrepreneurial history, 3(4), 234-256.

Hoselitz, B. F. (1959). Small industry in underdeveloped countries. The Journal of Economic History, 19(4), 600-618.

Jannuzzi, P. de M. (2003). Estratificação socioocupacional para estudos de mercado e pesquisa social no Brasil. São Paulo em Perspectiva, 17(34), 247-254.

Jones, G, \& Wadhwani, D. R. (2006). Entrepreneurship and business history: renewing the research agenda. Harvard Business School Working Paper. Cambridge: Harvard Business School

Kilby, P. (Ed.). (1971). Entrepreneurship and economic development. New York: The Free Press.

Light, I, \& Rosenstein, C. (1995). Race, ethnicity and entrepreneurship in urban American. New York: Aldine de Gruyter.

Marcovich, J. (2007). Pioneiros e empreendedores: a saga do desenvolvimento no Brasil. São Paulo: EDUSP \& Editora Saraiva

Martes, A. C. B, \& Rodriguez, C. L. (2004). Afiliação religiosa e empreendedorismo étnico: o caso dos brasileiros nos Estados Unidos. RAC-Revista de Administração Contemporânea, 8(3), 117-140.

Martes, A. C. B. Redes e Sociologia Economica. São Paulo: Fundação Getulio Vargas, 2009.

Martinelli, A. (2009). O contexto empreendedor. In A. C. B. Martes (Org.). Redes e sociologia econômica. São Carlos: Edufscar.

McCarthy, D. J. (2011). Classing early intervention: social class, occupational moralities and criminalization. Critical Social Policy, 31(4), 495-516.

Parsons, T. (1970). Equality and inequality in modern society, or social stratification revisited. Sociological Inquiry, 40(2), 13-72.

Parsons, T. (1974). O sistema das sociedades modernas. São Paulo: Pioneira.

Pastore, J, \& Silva, N. (1999). Mobilidade social no Brasil. São Paulo: Makron Books.

Pereira, B. (1964). Origens étnicas e sociais do empresário paulista. RAE-Revista de Administração de Empresas, 11(4), 83-106.

Pochmann, M. (2010). Estrutura social no Brasil: mudanças recentes. Serviço Social, 104, 637-649.

Portes, A. (1995). Economic sociology and sociology of immigration: a conceptual overview. In A. Portes (Ed.). The economic sociology of immigration: essays in networks, ethnicity and entrepreneurship. (pp. 1- 41)
Ramos, L, \& Vieira, M. L. (2001). Desigualdade de rendimentos no Brasil nas décadas de 80 e 90: evolução e principais determinantes. (Texto para discussão n. 803). Rio de Janeiro: Ipea.

Ribeiro, C. A. C. (2007). Estrutura de classe e mobilidade social no Brasil. Bauru, São Paulo: Eduse.

Secretaria de Assuntos Estratégicos. (abril 2013). Vozes da nova classe média. (Caderno 3). Brasília: SAE.

Serviço Brasileiro de Apoio às Micro e Pequenas Empresas, \& Departamento Intersindical de Estatística e Estudos Socioeconômicos. (2011). Anuário do trabalho da micro e pequena empresa: 2010-2011, São Paulo: Dieese.

Simmel, G. (1986). Sociologia: estudios sobre las formas de la socialización. Madrid: Alianza Editorial (Obra original publicada em 1908).

Simmel, G. (2005). O estrangeiro (M. G. P. Koury, Trad.). RBSE, 4(12), 265-271 (Obra original publicada em 1908).

Sombart, W. (1928). Le bourgeois: contribuition à l'historie morale et intellectuelle de l'homme économique moderne. (S. Jankelevitch, Trad.). (Obra original publicada em 1909). Disponibilizado em formato eletrônico por Paquet, G. (2002). Recuperado em 12 maio, 2013, de http://www.uqac.uquebec.ca/zone30/Classiques_des_sciences_sociales/index.html

Sombart, W. (2001). The jews and modern capitalism. (M. Epstein, Trad.). Ontário: Batoche Books Limtied. (Obra original publicada em 1911).

Sorokin, P. (2001). Social and cultural mobility. In D. Grusky (Org.). Social stratification: class, race and gender in sociological perspective. Bolder: Westview Press.

Székely, M, Birdsall, N. Behrman, J. (2000). Intergerational mobility in Latin America: deeper markets and better schools make a difference. Birdsall, N. Behrman, J. (ed.) New markets, new opportunities? Washington: Brookings Instituion Press.

Tagliacarne, G. (1974). Pesquisa de mercado: técnica e prática. São Paulo: Atlas.

Truzzi, O. M, \& Neto, M. S. (2004). Economia e empreendedorismo étnico: balanço histórico da experiência paulista. In A. C. B. Martes (Org.). Redes e sociologia econômica. São Paulo: Fundação Getulio Vargas. (pp. 241-262).

Volery, T. (2007). Ethnic entrepreneurship: a theoretical framework. In L. P. Dana. Handbook of research on ethnic minority entrepreneurship: a co-evolutionary view on resource management. (pp. 30-41). Cheltenhan, UK: Edward Elgan Pusblishing Limited.

Waldinger, R, Aldrich, H. E, \& Ward, R. (1990). Ethnic entrepreneurs: immigrant business in industrial societies. Newbury Park: Sage Publications.

Werfhorst, H. G. Van de, \& Salverda, W. (2012). Consequences of economic inequality: introduction to a special issue. Research in Social Stratification and Mobility, 30(4), 377-387.

Zhao, W. (2012). Economic inequality, status perceptions, and subjective well-being in China's transitional economy. Research in Social Stratification and Mobility, 30(4), 433-450. 